\title{
Pancrelipase: an evidence-based review of its use for treating pancreatic exocrine insufficiency
}

This article was published in the following Dove Press journal:

Core Evidence

18 July 2012

Number of times this article has been viewed

\author{
Kei Nakajima' \\ Haruki Oshida' \\ Toshitaka Muneyuki ${ }^{2}$ \\ Masafumi Kakei \\ 'Division of Clinical Nutrition, \\ Department of Medical Dietetics, \\ Faculty of Pharmaceutical Sciences, \\ Josai University, Keyakidai, Sakado, \\ ${ }^{2}$ First Department of Comprehensive \\ Medicine, Saitama Medical Center, \\ Jichi Medical University School of \\ Medicine, Amanuma, Omiya, \\ Saitama, Japan
}

\begin{abstract}
Pancreatic exocrine insufficiency (PEI) is often observed in patients with pancreatic diseases, including chronic pancreatitis, cystic fibrosis, and tumors, or after surgical resection. PEI often results in malnutrition, weight loss and steatorrhea, which together increase the risk of morbidity and mortality. Therefore, nutritional interventions, such as low-fat diets and pancreatic enzyme replacement therapy (PERT), are needed to improve the clinical symptoms, and to address the pathophysiology of pancreatic exocrine insufficiency. PERT with delayed-release pancrelipase is now becoming a standard therapy for pancreatic exocrine insufficiency because it significantly improves the coefficients of fat and nitrogen absorption as well as clinical symptoms, without serious treatment-emergent adverse events. The major adverse events were tolerable gastrointestinal tract symptoms, such as stomach pain, nausea, and bloating. Fibrosing colonopathy, a serious complication, is associated with high doses of enzymes. Several pancrelipase products have been approved by the US Food and Drug Administration in recent years. Although many double-blind, placebo-controlled trials of pancrelipase products have been conducted in recent years, these studies have enrolled relatively few patients and have often been less than a few weeks in duration. Moreover, few studies have addressed the issue of pancreatic diabetes, a type of diabetes that is characterized by frequent hypoglycemia, which is difficult to manage. In addition, it is unclear whether PERT improves morbidity and mortality in such settings. Therefore, large, long-term prospective studies are needed to identify the optimal treatment for pancreatic exocrine insufficiency. The studies should also examine the extent to which PERT using pancrelipase improves mortality and morbidity. The etiology and severity of pancreatic exocrine insufficiency often differ among patients with gastrointestinal diseases or diabetes (type 1 and type 2), and among elderly subjects. Finally, although there is currently limited clinical evidence, numerous extrapancreatic diseases and conditions that are highly prevalent in the general population may also be considered potential targets for PERT and related treatments.
\end{abstract}

Keywords: pancreatic exocrine insufficiency, chronic pancreatitis, pancreatic diabetes, steatorrhea, pancreatic enzyme replacement therapy, extrapancreatic diseases

Core evidence Clinical impact summary for pancrelipase and pancreatic exocrine insufficiency

\begin{tabular}{|lll|}
\hline Outcome measure & Evidence & Implications \\
\hline $\begin{array}{l}\text { Disease-oriented } \\
\text { evidence }\end{array}$ & $\begin{array}{l}\text { Randomized, double-blind, placebo- } \\
\text { controlled trials showed that pancreatic } \\
\text { enzyme replacement therapy with } \\
\text { pancrelipase even for short periods of a } \\
\text { few weeks improved steatorrhea and the } \\
\text { coefficient of fat absorption and of } \\
\text { nitrogen absorption along with increase in }\end{array}$ & $\begin{array}{l}\text { Pancrelipase improves } \\
\text { maldigestion and } \\
\text { malnutrition, which } \\
\text { leads to restoration of } \\
\text { nutritional conditions, } \\
\end{array}$ \\
& & \\
& & irrespective of age \\
& & (Continued) \\
\hline
\end{tabular}

Correspondence: Kei Nakajima

Division of Clinical Nutrition,

Department of Medical Dietetics, Faculty of Pharmaceutical Sciences, Josai University, I-I Keyakidai, Sakado, Saitama, 350-0295, Japan

Tel $+8|4927| 7260$

$\mathrm{Fax}+814927 \mid 7260$

Email keinaka@josai.ac.jp 


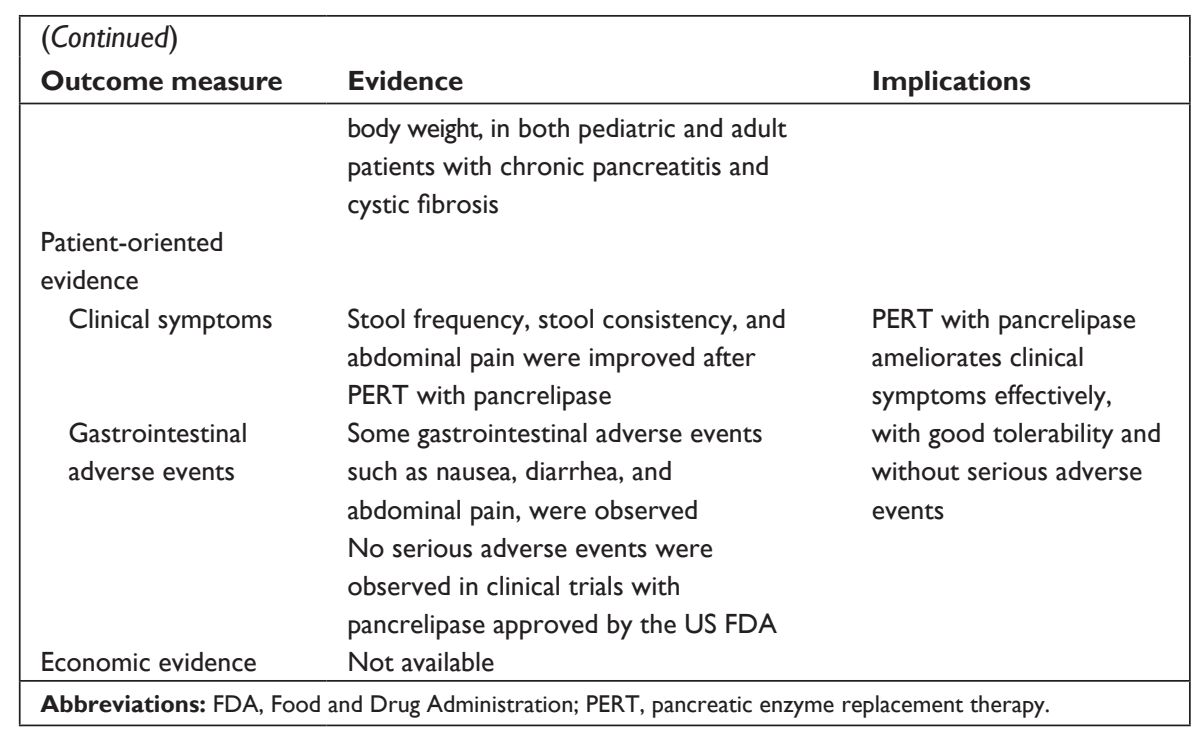

\section{Introduction}

The pancreas is a major organ that regulates food digestion and absorption in harmonization with other organs. Pancreatic diseases are associated with deterioration of the pancreatic parenchyma and of the dual physiological functions of pancreas (ie, its exocrine and endocrine functions). This deterioration occurs over several years to decades, and involves atrophic/ fibrotic changes that ultimately result in pancreatic exocrine insufficiency (PEI) and pancreatic endocrine insufficiency (eg, pancreatic diabetes). ${ }^{1-5}$

PEI is often observed in individuals with chronic pancreatitis, cystic fibrosis, and pancreatic tumors, or after surgical resection of the pancreas (Figure 1). ${ }^{1-4}$ During progression of pancreatic disease, PEI is associated with malnutrition, including low levels of micronutrients and fat-soluble vitamins, particularly vitamin $\mathrm{D}$, and essential fatty acids, coupled with gradual weight loss and steatorrhea as a result of maldigestion. This issue is particularly important in children because malnutrition may affect growth patterns. Therefore, lifestyle (eg, cessation of alcohol and smoking), nutritional (eg, low-fat diet and dietary supplementation with essential minerals and vitamins), and pharmacological interventions are needed to improve the clinical symptoms and pathophysiology of pancreatic diseases. For example, pancreatic enzyme replacement therapy (PERT) not only improves the clinical symptoms and malnutrition caused by PEI, but can also allow the patient to discontinue a low-fat diet.

This review summarizes the current evidence for the effectiveness of PERT with pancrelipase products approved for different indications, referring to literature indexed in PubMed. We also discuss use of the available pancrelipase products for treating PEI caused predominantly by pancreatic diseases. We also describe the potential use of PERT with pancrelipase for treating various extrapancreatic conditions.

\section{Pancrelipase products approved for PERT}

PERT using pancrelipase products, which are mostly purified from the porcine pancreas, have been tested extensively for PEI associated with pancreatic diseases. ${ }^{4,6-9}$ Pancreatic enzyme products have been available as over-the-counter drugs in many countries, including the US and Europe (eg, France, Germany, Italy, Spain, and the UK) for several decades. ${ }^{9}$ However, because of the potential adverse effects and limited effectiveness, some drug regulatory agencies, including the US Food and Drug Administration (FDA), have required the manufacturers to obtain regulatory approval before they can market their products.

Many pancrelipase products have been introduced to treat PEI. Two of these products, pancrelipase and pancreatin, are the major pancreatic enzymes produced in the porcine pancreas, with pancrelipase showing greater expression. ${ }^{8}$ Although several reports have suggested that bovine enzyme products may offer an alternative to porcine enzymes, bovine enzymes are still rarely used in many countries ${ }^{10}$ because their lipase activity is approximately $75 \%$ lower than that of the corresponding porcine enzymes. ${ }^{8}$ Pancreatic exocrine enzymes manufactured by gene transfer techniques may soon replace animal-derived enzymes and are currently under clinical development.

Of the three major pancreatic enzymes, lipase is the most susceptible to loss or degradation after administration. Current therapeutic concepts recommend the administration 


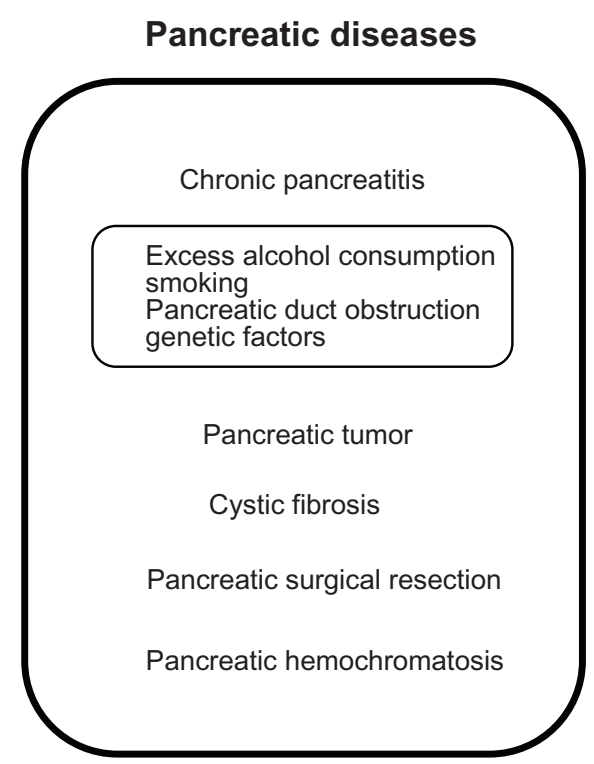

Figure I Relationship between pancreas diseases, PEI, and pancreatic diabetes. Abbreviation: PEI, pancreatic exocrine insufficiency.

of 25,000-50,000 units of porcine lipase per meal, when administered using $\mathrm{pH}$-sensitive pancreatin microspheres, or 20,000-25,000 units for snacks. ${ }^{11}$ These doses may be increased by up to three-fold until sufficient clinical improvements are observed. The administration of bicarbonate or acid suppressers, preferably proton pomp inhibitors, is often necessary to prevent acid-mediated inactivation of enzymes, although enteric-coated enzyme products are increasingly being used to avoid this problem. If the response remains inadequate, bacterial overgrowth in the small intestine should be considered and treated. ${ }^{12}$

Currently, all of the enzyme products used for PERT are of porcine origin. Therefore, it is possible that allergic

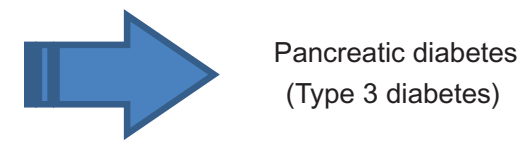

Endocrine dysfunction

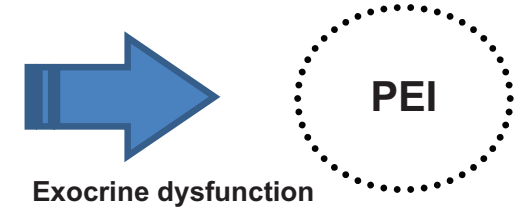

Table I Available pancrelipase products approved by the US Food and Drug Administration

\begin{tabular}{|c|c|c|c|}
\hline Drug & Active ingredients & Time of FDA approval & Strength (amylase, lipase, and protease) \\
\hline \multirow[t]{3}{*}{ Creon $^{\circledast}$} & Capsule, delayed release; oral & 2009 & 30,000 USP U; 6000 USP U; I9,000 USP U \\
\hline & & & 60,000 USP U; 12,000 USP U; 38,000 USP U \\
\hline & & & I20,000 USP U; 24,000 USP U; 76,000 USP U \\
\hline \multirow[t]{4}{*}{ Zenpep ${ }^{\circledR}$} & Capsule, delayed release, oral & 2009 & 27,000 USP U; 5000 USP U; 17,000 USP U \\
\hline & & & 55,000 USP U; 10,000 USP U; 34,000 USP U \\
\hline & & & 82,000 USP U; 15,000 USP U; 51,000 USP \\
\hline & & & 109,000 USP U; 20,000 USP U; 68,000 USP U \\
\hline \multirow[t]{4}{*}{ Pancreaze $^{\circledR}$} & Capsule, delayed release, oral & 2010 & I7,500 USP U; 4200 USP U; 10,000 USP U \\
\hline & & & 43,750 USP U; 10,500 USP U; 25,000 USP U \\
\hline & & & 61,000 USP U; 21,000 USP U; 37,000 USP U \\
\hline & & & 70,000 USP U; 16,800 USP U; 40,000 USP U \\
\hline \multirow[t]{3}{*}{ Ultresa $^{\circledR}$} & Capsule, delayed release, oral & 2012 & 27,600 USP U; 13,800 USP U; 27,600 USP U \\
\hline & & & $4 I, 400$ USP U; 20,700 USP U; 4I,400 USP U \\
\hline & & & 46,000 USP U; 23,000 USP U; 46,000 USP U \\
\hline \multirow[t]{2}{*}{ Viokace $^{\circledR}$} & Tablet, oral & 2012 & 39,150 USP U; 10,440 USP U; 39, I50 USP U \\
\hline & & & 78,300 USP U; 28,880 USP U; 78,300 USP U \\
\hline
\end{tabular}

Abbreviations: FDA, Food and Drug Administration; USP U, United States Pharmacopeia units. 
approved by the Ministry of Health, Labour, and Welfare in 2011 for PEI caused by chronic pancreatitis, pancreatectomy, cystic fibrosis, and other conditions.

Overall, many clinical trials of pancrelipase products approved by the FDA have been conducted in recent years. These studies have shown various degrees of improvement in steatorrhea and malnutrition with a low risk of adverse effects, including tolerable gastrointestinal tract symptoms, in patients with chronic pancreatitis, cystic fibrosis, and pancreatic resection (Table 2). However, most of these studies enrolled relatively few patients and were often less than a few weeks in length. Moreover, few studies have addressed the issue of pancreatic diabetes, another clinical aspect of chronic pancreatitis and cystic fibrosis, which is likely to be affected by PERT through increased absorption of carbohydrates. It is also unknown whether PERT using pancrelipase products improves morbidity and mortality, which should be examined in long-term prospective clinical studies.

Another issue regarding the use of PERT is that, contrary to initial expectations, PEI is a highly heterogeneous disease. As shown in Figure 2, PEI is also observed in patients with extrapancreatic diseases and conditions, gastrointestinal diseases, diabetes (both type 1 and type 2), and in the elderly.,5,13-17 In particular, the prevalence of extrapancreatic diseases (eg, type 2 diabetes) and of associated conditions in elderly individuals is substantially higher than those of "traditional" pancreas diseases, considering that chronic pancreatitis is detected in $0.04 \%-5 \%$ of all autopsies, ${ }^{18}$ and cystic fibrosis is a rare genetic disease. ${ }^{2}$ Furthermore, the prevalence of extrapancreatic diseases and conditions is rapidly increasing worldwide because of the obesity pandemic and prolonged longevity. ${ }^{19,20}$ Although these emerging PEIs are likely to predispose to malnutrition and increased risk of morbidity and/or mortality, the clinical relevance and application of PERT for these conditions have not been fully examined. Therefore, animal and clinical studies are needed to explore fully the underlying mechanisms and to determine the need for improving nutritional status and effects on morbidity/mortality in people with diabetes or gastrointestinal diseases, and in elderly individuals.

\section{Detection of $\mathrm{PEI}$ in routine clinical practice}

It is often difficult to detect PEI in routine clinical practice, particularly because patients are usually asymptomatic in the early stage of PEI. ${ }^{5}$ In addition, there is some controversy regarding the clinical applicability of the methods used to diagnose PEI. Nevertheless, for effective PERT, it is important to detect PEI as early and properly as possible.
In principle, the diagnosis of PEI should be based on standard methods such as the secretin-pancreozymin test or endoscopy. ${ }^{4,21}$ Other functional tests, including quantification of fat absorption and the ${ }^{13} \mathrm{C}$-mixed triglyceride breath test, ${ }^{12,21}$ are also useful to determine PEI associated with malabsorption. Several noninvasive and inexpensive tests, such as measurement of fecal elastase- 1 concentrations, are also useful to determine reduced pancreatic secretion in patients with different pancreatic diseases. ${ }^{5,21}$ Fecal elastase-1 is a proteolytic enzyme secreted exclusively from the pancreas. However, false-positive results are often observed in patients with intestinal diseases and diarrhea, presumably because of dilutional effects. ${ }^{21}$ In most cases, measuring the fecal concentrations of elastase (fecal elastase-1) may be sufficient to detect PEI, ${ }^{22}$ because elastase concentrations show higher sensitivity for PEI compared with chymotrypsin concentrations. ${ }^{4,23}$ In this context, fecal elastase- 1 concentration may be considered as a standard clinical marker for PEI, particularly moderate to severe PEI. ${ }^{23}$

However, clinicians must be aware that abnormal concentrations of these markers may reflect advanced stages of PEI. In addition, clinical symptoms such as steatorrhea may not occur until more than $90 \%$ of the pancreatic parenchyma is lost. ${ }^{24,25}$ Therefore, replacing $\geq 10 \%$ of endogenous pancreatic enzymes is required for food digestion and may be sufficient to manage the clinical symptoms.

\section{Pancreatic diseases and PERT Chronic pancreatitis}

Chronic pancreatitis is characterized by irreversible destruction of pancreatic tissue, and results in pancreatic exocrine and endocrine insufficiency. In developed countries, alcohol is responsible for up to $80 \%$ of cases of chronic pancreatitis in adults. ${ }^{26}$ Although smoking has received less attention than alcohol in terms of understanding the pathogenesis of chronic pancreatitis, smoking is also associated with chronic pancreatitis, pancreatic calcification, and PEI, even after adjusting for alcohol intake and other risk factors. ${ }^{27,28}$ In fact, we showed that current smoking was significantly associated with low serum amylase, a possible marker for pancreatic exocrine dysfunction, in a general population..$^{29}$ Therefore, drinking of alcohol and smoking, including past smoking, may contribute to the development and progression of chronic pancreatitis and PEI. In children, genetic and anatomic factors seem to contribute to the pathogenesis of chronic pancreatitis. ${ }^{30,31}$

Although therapies for chronic pancreatitis include opioids, endoscopy, and surgery, ${ }^{31}$ standard treatment for PEI consists of PERT along with dietary interventions. 


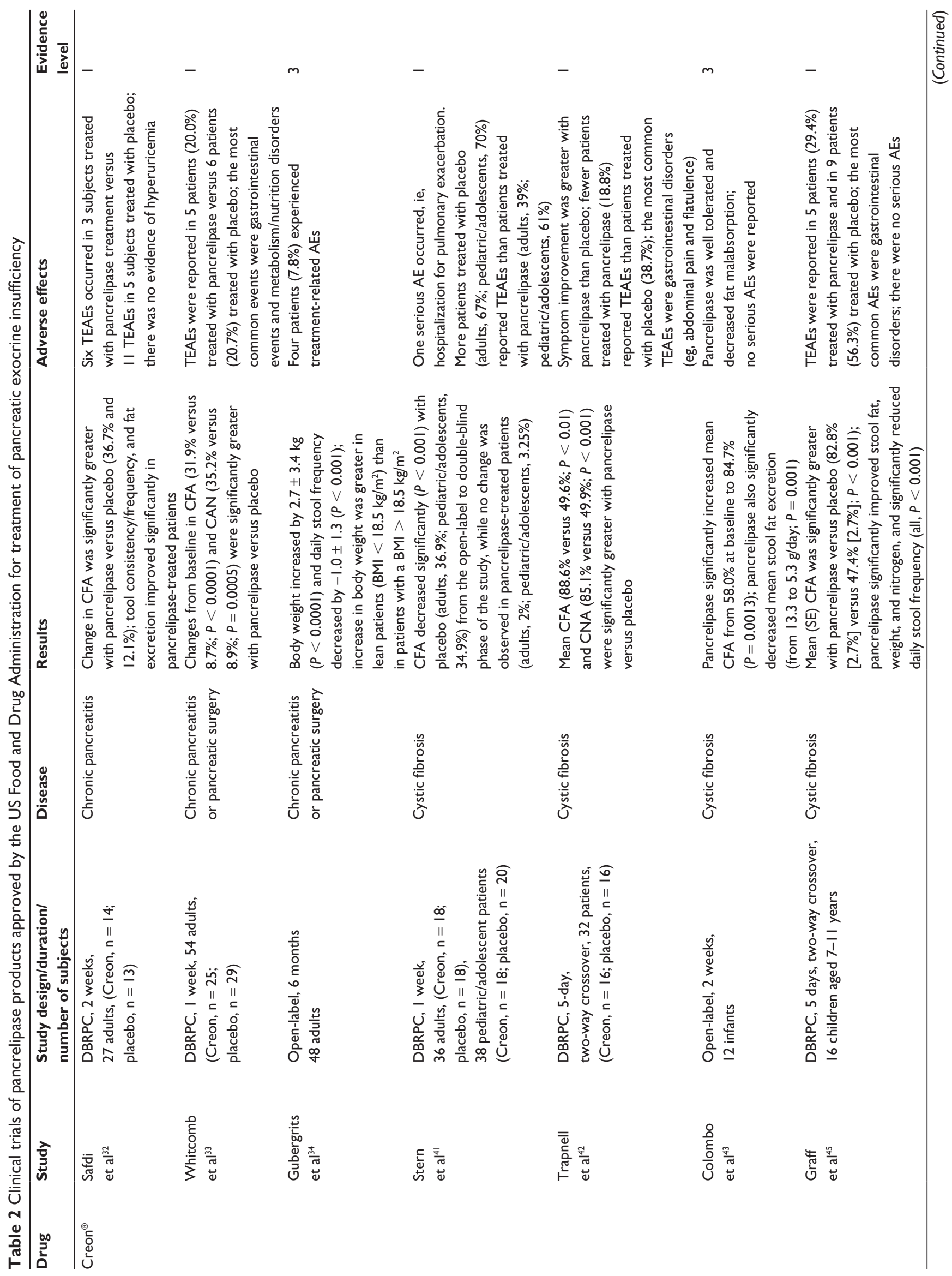




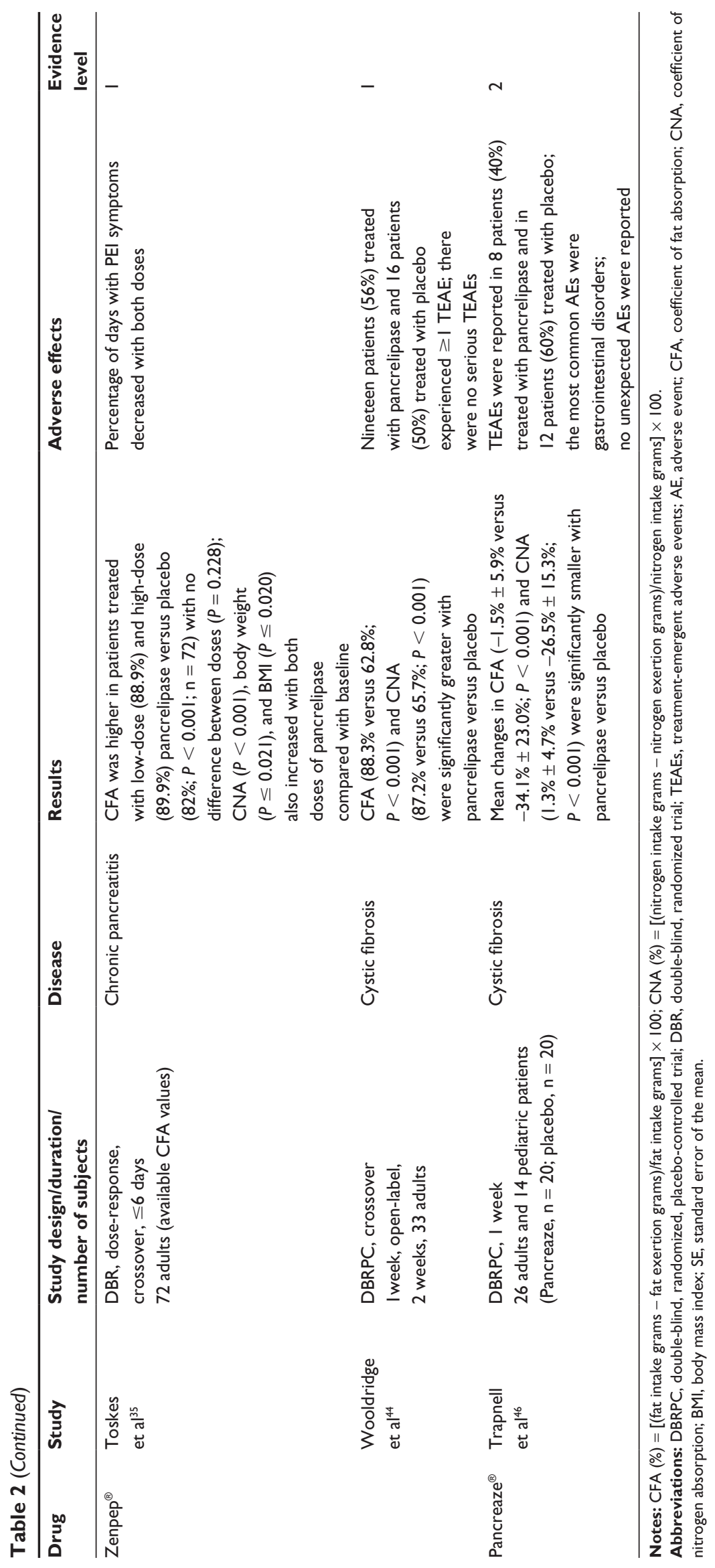




\section{Extrapancreatic conditions}

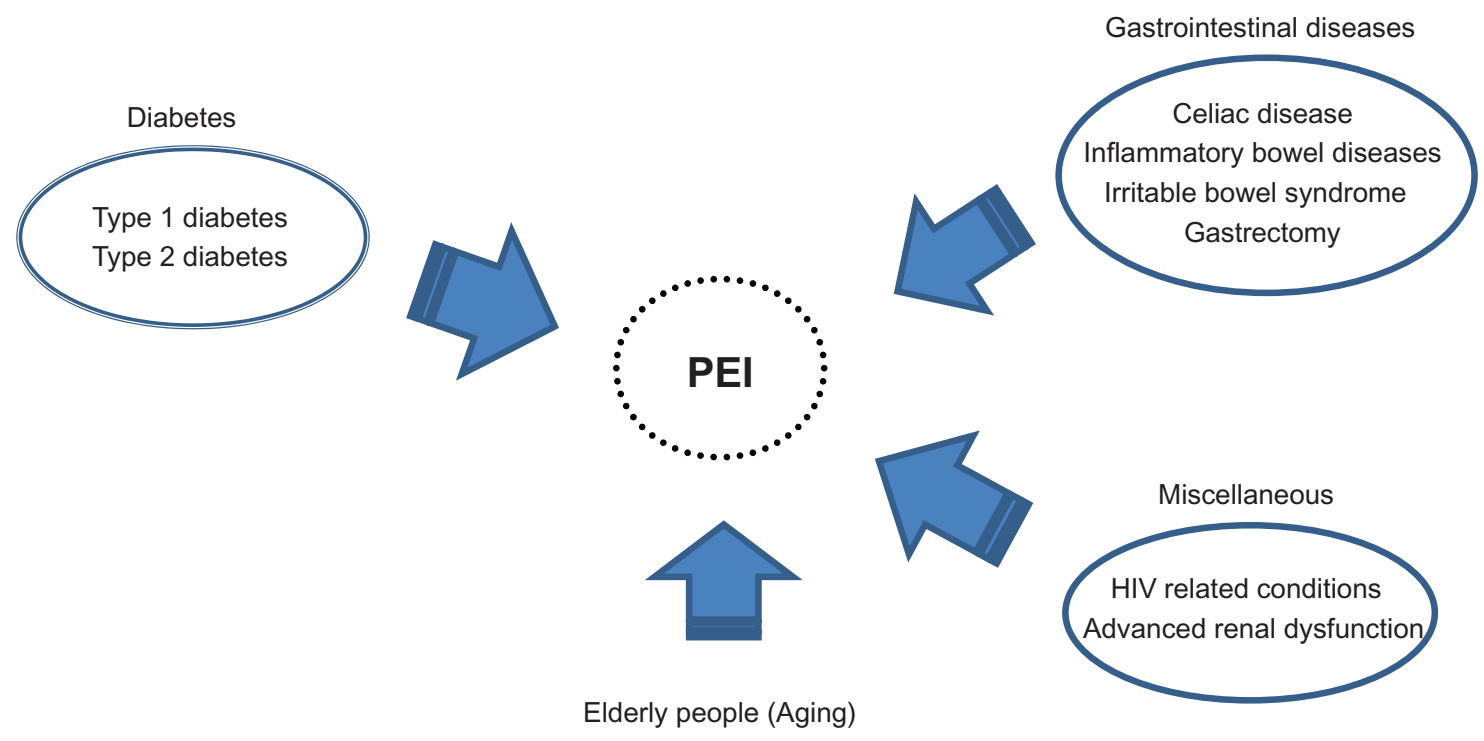

Figure 2 Relationship between extrapancreatic diseases/conditions and PEI.

Abbreviation: PEI, pancreatic exocrine insufficiency.

In terms of specific pharmacotherapies, two double-blind, randomized, placebo-controlled studies by Safdi et $\mathrm{al}^{32}$ and Whitcomb et $\mathrm{al}^{33}$ revealed that pancrelipase (Creon) substantially improved clinical symptoms, including stool consistency and abdominal pain, in patients with chronic pancreatitis (Table 2). In a recent open-label clinical trial, the administration of delayed-release pancrelipase capsules (Creon) resulted in significant weight gain and reduced stool frequency in 48 patients with PEI caused by chronic pancreatitis or pancreatic surgery. ${ }^{34}$ Similarly, treatment with low-dose Zenpep ${ }^{\circledR} 7 \times 5000$ lipase units/day significantly increased the coefficients of fat absorption and nitrogen absorption in patients with chronic pancreatitis. ${ }^{35}$

Based on these and other studies, several pancrelipase products are now being used to treat PEI associated with chronic pancreatitis and other diseases. There are no marked differences in the cost of the currently available products. ${ }^{36}$ In addition, treatment-emergent adverse events observed in clinical trials of PERT, which were mostly mild and tolerable gastrointestinal symptoms such as abdominal pain were generally similar to those observed with placebo.

Worryingly, the mortality rate of patients with chronic pancreatitis is 3-4-fold higher than that of the general population, while the 20 -year survival rate is less than $50 \%{ }^{37}$ Clinical studies examining the effects of pancrelipase on long-term mortality are currently lacking, and long-term double-blind, randomized, placebo-controlled studies, if possible, are needed to determine whether pancrelipase reduces the risk of mortality in addition to improving clinical symptoms in patients with PEI caused by chronic pancreatitis.

\section{Cystic fibrosis}

PEI occurs in approximately $85 \%$ of patients with cystic fibrosis. ${ }^{38}$ Cystic fibrosis is a rare autosomal recessive disease that affects pancreatic function and lung function from birth. In cystic fibrosis, the secretion of thick mucus is increased in the lungs and pancreas, eventually leading to dyspnea and blocking the secretion of pancreatic enzymes. The condition is caused by mutations in a single gene on chromosome 7 , which encodes the cystic fibrosis transmembrane conductance regulator. ${ }^{39}$

Standard therapy for cystic fibrosis includes chest physical therapy, aerosolized antibiotics, mucus-thinning drugs, and PERT. ${ }^{40}$ In addition, people with cystic fibrosis are recommended to increase their intake of calories, protein, fat, and appropriate minerals and vitamins. Patients with cystic fibrosis are at increased risk of malnutrition as a result of nutrient malabsorption, leading to growth failure in children. On this basis, PERT is essential for children and young patients with cystic fibrosis.

Several double-blind, randomized, placebo-controlled studies and an open-label study have shown that treatment with pancrelipase products (eg, Creon, Zenpep, Pancreaze ${ }^{\circledR}$ ) improves the coefficients of fat and nitrogen absorption and clinical symptoms in patients with cystic fibrosis compared with placebo, with favorable safety profiles (Table 2). ${ }^{41-46}$ In a double-blind crossover trial by Wooldridge et al, ${ }^{44}$ a higher 
coefficient of fat absorption were observed during the pancrelipase period compared with placebo, particularly in patients with a lower coefficient of fat absorption at baseline (Figure 3). In addition, pancrelipase improved fat absorption, as shown by a significantly lower change in the coefficient of fat absorption between the open-label and double-blind phases for pancrelipase $(-1.5 \% \pm 5.9 \% ; P<0.001)$ compared with placebo (-34.1\% $\pm 23.0 \%$, Figure 4$)$. Thus, pancrelipase products are likely to improve PEI secondary to cystic fibrosis.

Olveira and Olveira ${ }^{47}$ reported that most patients with PEI can tolerate high-fat diets providing they are treated with appropriate doses of pancreatic enzymes. These results suggest that low-fat diets may not be necessary when nutrient malabsorption has been corrected with appropriate PERT. They also noted that if nutritional goals are not achieved or maintained with dietary modifications, supplements may be added to improve nutritional status, including via enteral or parenteral nutritional support where necessary.

\section{Pancreatic resection}

Partial or total pancreatectomy immediately causes PEI, meaning PERT is essential to maintain adequate digestion. Partial pancreatectomy is sometimes carried out in patients with chronic pancreatitis and intolerable pain, in those with evidence of necrosis in pancreatic tissue, ${ }^{48}$ and in patients with a pancreatic tumor. Similar to PEI in patients with chronic pancreatitis or cystic fibrosis, PEI occurring after pancreatectomy can be treated with pancrelipase products, with good tolerability. ${ }^{33,34}$

\section{Enteral nutrition}

The studies described above suggest that PERT is likely to improve clinical symptoms and malnutrition, irrespective of the clinical manifestations and cause of PEI. However, in clinical practice, PERT may be necessary for patients who are unable to swallow tablets, capsules, or granules. In such cases, enteral feeding tubes can be used to administer the pancreatic enzymes. Indeed, Ferrie et $\mathrm{al}^{49}$ reported that pancreatic enzyme supplementation can continue during enteral feeding via gastric tubes. In addition, Shlieout et $\mathrm{al}^{50}$ reported that pancrelipase capsules (Creon) can be mixed with baby food at $\mathrm{pH}<4.5$ and administered via gastric tubes without clogging, sticking, or visible pellet damage, and without loss of gastric resistance or lipase activity. These results suggest that PERT can be performed during enteral nutrition.

\section{Adverse effects of pancrelipase}

Although some gastrointestinal events were observed in individuals who received pancrelipase, no serious adverse effects were observed in recent clinical trials (Table 2). The major adverse effects included stomach pain, nausea, bloating, headache, and dizziness. Although hyperuricemia was reported in patients with cystic fibrosis treated with pancreatic enzyme products, ${ }^{51}$ the most recent studies have found no significant association between the use of pancrelipase and hyperuricemia. ${ }^{32,41}$ Fibrosing colonopathy, a serious complication of cystic fibrosis, can develop several months to several years after starting high-dose PERT. ${ }^{52}$ Generally, high doses of enzymes (eg, $>75,000$ units/meal for adults and $>25,000$ units/meal for children) are not recommended, ${ }^{7,50}$ nor are doses of lipase $>2500$ units $/ \mathrm{kg} / \mathrm{meal}$ (10,000 units/kg/day).${ }^{53}$ The Cystic Fibrosis Foundation recommended in their consensusbased guidelines that dosages should be limited to 500-2500 lipase units $/ \mathrm{kg} / \mathrm{meal},<10,000$ lipase units/kg/day, or $<4000$ lipase units/g dietary fat/day. ${ }^{54}$ Although the pathogenesis of fibrosing colonopathy is unknown, it is highly correlated

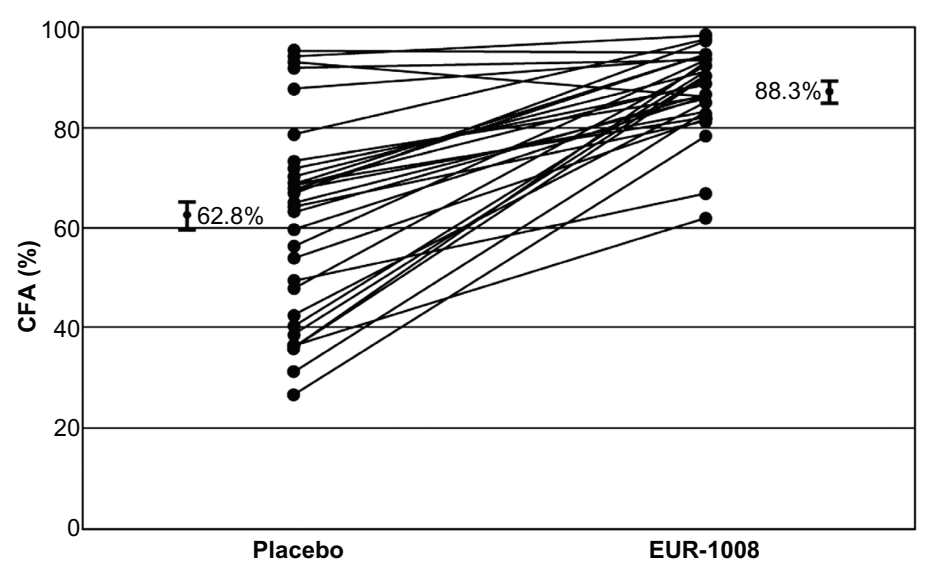

Figure 3 Plots of the individual patient values of CFA during placebo and EUR- 1008 (Zenpep [Pancrelipase]). Bars on the far left and right of figure indicate the least-squares means and the standard error of CFA during placebo $(62.8 \pm 2.6 \%)$ vs CFA during EUR-1008 treatment ( $88.3 \pm 2.6 \%)$. All patients had fecal elastase (monoclonal assay) of $<100 \mu \mathrm{g} / \mathrm{g}$ stool at screening.

Abbreviation: CFA, coefficient of fat absorption. 

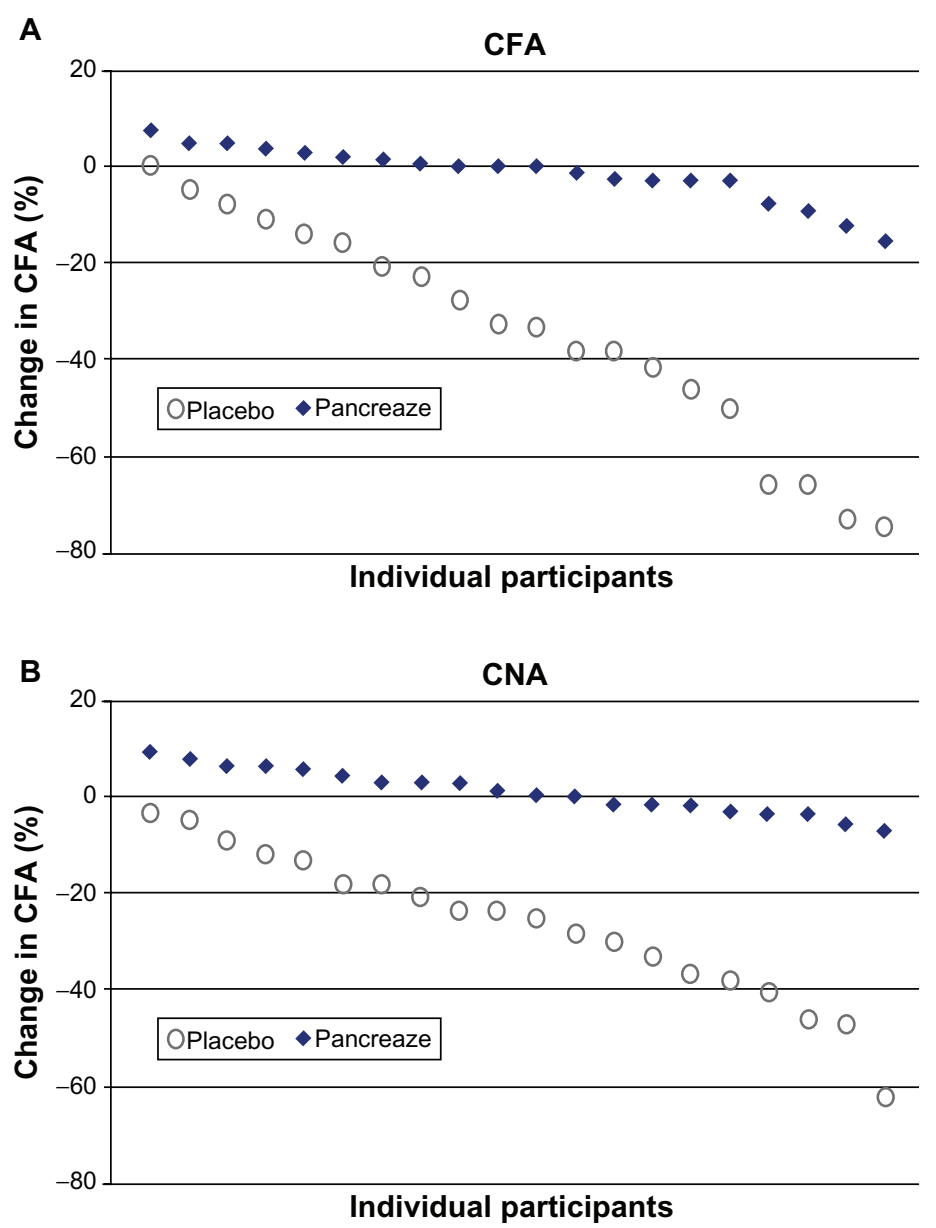

Figure 4 Individual participant data for (A) change in CFA and (B) change in CNA between the open-label phase (all participants received Pancreaze ${ }^{\circledR}$ ) and double-blind phase for placebo $(n=20)$ or Pancreaze ${ }^{\circledast}(n=20)$.

Abbreviations: CFA, coefficient of fat absorption; CNA, coefficient of nitrogen absorption.

with pancreatic enzyme dose, the clinical features of Crohn's disease, and ischemic bowel disease, ${ }^{52}$ and compounds present in enteric coatings designed to protect the enzymes against gastric acid. ${ }^{55}$ Lee et al ${ }^{56}$ also proposed that local injury caused by proteases or immune activity may be responsible for the pathological changes in fibrosing colonopathy.

\section{Pancreatic diabetes as a complication of pancreatic disease}

It is well known that pancreatic disorders (eg, chronic pancreatitis, cystic fibrosis, and pancreatic surgical resection) cause endocrine dysfunction, known as pancreatic diabetes, through the progressive destruction of pancreatic tissue (Figure 1). Kahl and Malfertheiner ${ }^{57}$ reported that hypoglycemia is particularly difficult to manage after total pancreatectomy. Except for pancreatic resection, the etiology of pancreatic diabetes is not fully understood, probably because of its complicated phenotype and pathophysiology in comparison with type 1 and type 2 diabetes. In pancreatic diabetes, secretion of pancreatic endocrine hormones (ie, insulin, glucagon, and pancreatic polypeptide) is impaired, ${ }^{58}$ eventually resulting in brittle diabetes associated with hyperglycemia and frequent hypoglycemia (Table 3). Since people with pancreatic diabetes are often nonobese or lean with malnutrition, they are occasionally misdiagnosed and treated with inappropriate drugs and diet. Pancreatic diabetes may be more common than currently believed, accounting for up to $9 \%$ of all cases of diabetes. ${ }^{59,60}$ By contrast, a nationwide study in Japan showed that pancreatic diabetes accounted for $0.8 \%$ of patients with total diabetes.$^{61}$ There might also be a racial difference in the prevalence of pancreatic diabetes.

In moderate to advanced pancreatic diabetes, insulin injection is necessary to treat hyperglycemia. However, this may result in sudden hypoglycemia because of insufficient glucagon secretion and the absence of peripheral insulin resistance. ${ }^{58}$ Surprisingly, hepatic insulin resistance is quite common in patients with pancreatic diabetes associated with chronic pancreatitis. ${ }^{58,62}$ Hepatic insulin resistance results in upregulated hepatic glucose production and impaired hepatic glucose disposal. 
Table 3 Various features of different types of diabetes

\begin{tabular}{llll}
\hline & Type I diabetes & Type 2 diabetes & Type 3 pancreatogenic diabetes \\
\hline Ketoacidosis & Common & Rare & Rare \\
Hyperglycemia & Severe & Usually mild & Mild \\
Hypoglycemia & Common & Rare & Common \\
Peripheral insulin sensitivity & Normal or increased & Decreased & Increased \\
Hepatic insulin sensitivity & Normal & Normal or decreased & Decreased \\
Insulin levels & Low & High & Low \\
Glucagon levels & Normal or high & Normal or high & Low \\
Pancreatic polypeptide levels & High & High & Low \\
Typical age of onset & Childhood or adolescence & Adulthood & Any \\
\hline
\end{tabular}

C2012, Springer. Reproduced with permission from Slezak LA, Andersen DK. Pancreatic resection: effects on glucose metabolism. World J Surg. 200I;25(4):452-460.

Unfortunately, it is unknown whether PERT improves the pathophysiology of pancreatic diabetes because no clinical trials have tested this possibility. PERT with pancrelipase increases fat, protein, and carbohydrate absorption. Therefore, PERT is expected to worsen glucose metabolism by increasing glucose transport from intestine to the circulation. Consistently, the prescribing information for Creon, which is manufactured by Abbott Laboratories (North Chicago, IL), lists "blood sugar increase (hyperglycemia) or decrease (hypoglycemia)" as a common side effect. However, increased glucose absorption could reduce the risk of hypoglycemia, allowing more aggressive treatment of hyperglycemia with oral medications and insulin. Cui and Andersen ${ }^{62}$ proposed that metformin should be the first-line therapy for pancreatic diabetes because of the possible risk of cancer with insulin and insulin secretagogues.

Based on the clinical characteristics of diabetes, three types can be distinguished (Table 3), although pancreatic diabetes could occur in combination with other forms. For example, in drinkers, pancreatic diabetes may be caused by chronic pancreatitis associated with chronic alcohol intake, while type 2 diabetes may occur as a result of obesity, overeating, infrequent exercise, and smoking in the same individual. Given that smoking is associated with chronic pancreatitis ${ }^{27,28}$ and type 2 diabetes, ${ }^{63,64}$ often it may be hard to differentiate between pancreatic diabetes and type 2 diabetes in actual clinical practice. Therefore, the fundamental type of diabetes may be complicated in some individuals, representing a combination of type 2 diabetes and pancreatic diabetes.

\section{Extrapancreatic diseases and conditions}

PEI is also common in patients with extrapancreatic diseases. Several trials have been conducted to examine possible treatments of PEI associated with extrapancreatic disease (Table 4). Although the drug used in these studies was mostly pancreatin instead of pancrelipase, the results may be meaningful in the consideration of PERT for extrapancreatic disease and conditions.

\section{Gastrointestinal diseases}

\section{Celiac disease}

Celiac disease is an inflammatory intestinal disease that causes intolerance to gluten present in foods such as wheat and rye. The clinical symptoms include diarrhea and other gastrointestinal disorders caused by maldigestion and malabsorption of nutrients and vitamins. The mainstay treatment is a gluten-free diet, which improves gastrointestinal function, corrects diarrhea, and enables weight gain. However, strict adherence to a gluten-free diet is not effective in all patients. ${ }^{65}$ Indeed, chronic diarrhea may persist in many patients, suggesting other factors are involved in this disease. ${ }^{66}$

The prevalence of celiac disease in the general population, as assessed by screening of healthy volunteers in the US, UK, and other European countries, was $0.5 \%-1 \%{ }^{67-69}$ Celiac disease is frequently associated with PEI, ${ }^{70,71}$ possibly because of increased immune activity in the intestinal tract. Evans et $\mathrm{al}^{70}$ showed that in a study of 20 patients with celiac disease, diarrhea was improved in 19 patients given PERT at a mean dose of 45,000 lipase units/day. Leeds et $\mathrm{al}^{72}$ also showed that low fecal elastase content is more common in patients with celiac disease and chronic diarrhea, and that PERT in combination with a gluten-free diet reduced stool frequency from four per day to one.

\section{Irritable bowel syndrome}

Irritable bowel syndrome is a common functional gastrointestinal disorder that affects up to $15 \%$ of the general population 
Table 4 Clinical trials for treatment of pancreatic exocrine insufficiency in extrapancreatic diseases and diabetes

\begin{tabular}{|c|c|c|c|c|c|}
\hline Authors & $\begin{array}{l}\text { Study design, duration, } \\
\text { and number of subjects }\end{array}$ & Disease/drug & Results & Adverse effects & $\begin{array}{l}\text { Evidence } \\
\text { level }\end{array}$ \\
\hline $\begin{array}{l}\text { Evans } \\
\text { et } \mathrm{al}^{70}\end{array}$ & $\begin{array}{l}\text { Prospective study, } \\
\text { months to } 4 \text { years, } \\
19 \text { adults }\end{array}$ & $\begin{array}{l}\text { Celiac disease/ } \\
\text { Creon }^{\circledR} \text { (pancreatin) }\end{array}$ & $\begin{array}{l}\text { There was an increase in fecal } \\
\text { elastase-I levels over time, with } \\
\text { median of } 90 \mu g / g \text { at } 0 \text { months, } \\
212 \mu g / g \text { at } 6 \text { months, and } \\
365 \mu g / g \text { at follow-up } \\
(P<0.000 \mathrm{I}) \text { in patients who } \\
\text { received PERT throughout }\end{array}$ & $\begin{array}{l}\text { Overall, } 8 / 19 \text { patients had } \\
\text { discontinued supplementation } \\
\text { because their diarrhea had } \\
\text { improved; only I/II reported } \\
\text { no symptomatic benefit }\end{array}$ & 3 \\
\hline $\begin{array}{l}\text { Leeds } \\
\text { et } \mathrm{a}^{72}\end{array}$ & $\begin{array}{l}\text { Open-label, } \\
\text { up to } 2 \text { years } \\
20 \text { adults }\end{array}$ & $\begin{array}{l}\text { Celiac disease } \\
\text { Unknown }\end{array}$ & $\begin{array}{l}\text { In } 18 \text { of } 20 \text {, stool frequency } \\
\text { reduced following pancreatic } \\
\text { enzyme supplementation from } \\
\text { four daily to one daily } \\
(P<0.00 \text { I }) \text {; no weight increase } \\
\text { was observed; all patients had } \\
\text { duodenal histological } \\
\text { improvement }\end{array}$ & $\begin{array}{l}\text { No description regarding } \\
\text { TEAEs }\end{array}$ & 4 \\
\hline $\begin{array}{l}\text { Leeds } \\
\text { et } \mathrm{al}^{74}\end{array}$ & $\begin{array}{l}\text { Open-label, } \\
6 \text { and } 12 \text { weeks, } \\
34 \text { adults }\end{array}$ & $\begin{array}{l}\text { Irritable bowel } \\
\text { syndrome } \\
\text { Creon }\end{array}$ & $\begin{array}{l}\text { Improvements in stool } \\
\text { frequency (from median } 6 \text { to less } \\
\text { than } 2 \text { daily, } P<0.00 \mathrm{I}) \text {, stool } \\
\text { consistency }(P<0.00 \mathrm{I}) \text {, and } \\
\text { abdominal pain }(P=0.003 \text { ) were } \\
\text { observed in patients with fecal } \\
\text { elastase-I levels less than } \\
\mathrm{I} 00 \mu \mathrm{g} / \mathrm{g} \text { stool }\end{array}$ & $\begin{array}{l}\text { No major side effects were } \\
\text { reported; some patients } \\
\text { felt nausea but no patients } \\
\text { stopped therapy }\end{array}$ & 3 \\
\hline $\begin{array}{l}\text { Ewald } \\
\text { et } \mathrm{al}^{85}\end{array}$ & $\begin{array}{l}\text { DBRPC, } 16 \text { week, } \\
80 \text { adults (Creon } 39 \\
\text { and placebo 4I) }\end{array}$ & $\begin{array}{l}\text { Type I diabetes } \\
\text { Creon (pancreatin) }\end{array}$ & $\begin{array}{l}\text { There were no significant } \\
\text { differences between pancreatin } \\
\text { group and placebo group } \\
\text { concerning } \mathrm{HbA}_{\mathrm{lc}} \text {, fasting } \\
\text { glucose levels, and 2-hour } \\
\text { glucose levels after oral glucose } \\
\text { tolerance test, clinical parameters }\end{array}$ & $\begin{array}{l}\text { TEAEs occurred in } 33 \text { patients } \\
(84.6 \%) \text { in pancreatin group and } \\
\text { in } 35(85.4 \%) \text { in placebo group; } \\
\text { most frequent adverse events } \\
\text { were headache, infection, } \\
\text { diarrhea, and dyspepsia }\end{array}$ & 3 \\
\hline $\begin{array}{l}\text { Knop } \\
\text { et } \mathrm{al}^{86}\end{array}$ & $\begin{array}{l}\text { Open-label, postprandial } \\
\text { (test meal) response } \\
8 \text { male adults }\end{array}$ & $\begin{array}{l}\text { Chronic pancreatitis } \\
\text { Creon }\end{array}$ & $\begin{array}{l}\text { The postprandial responses of } \\
\text { total GLP-I and total GIP were } \\
\text { increased (both } P=0.0 I \text { ) along } \\
\text { with increased plasma insulin } \\
\text { and total insulin secretion after } \\
\text { pancreatic enzyme substitution }\end{array}$ & $\begin{array}{l}\text { No description regarding } \\
\text { TEAEs }\end{array}$ & 3 \\
\hline
\end{tabular}

Abbreviations: DBRPC, double-blind, randomized, placebo-controlled trial; TEAEs, treatment-emergent adverse events; GLP-I, glucagon-like peptide-I; GIP, gastric inhibitory polypeptide; $\mathrm{HbA}_{\mathrm{lc}}$, glycosylated hemoglobin.

worldwide, and is characterized by unexplained abdominal pain, discomfort, and bloating. ${ }^{73}$ The pathophysiology of irritable bowel syndrome is complicated, but seems to involve dysfunction of the brain-gut axis. It was reported that PEI, as assessed by low fecal elastase- 1 concentrations, was detected in just $6.1 \%$ of patients who fulfilled the Rome II criteria for diarrhea-predominant irritable bowel syndrome. ${ }^{74}$ The causes of diarrhea in patients include exocrine pancreatic insufficiency. PERT improved stool frequency, stool consistency, and abdominal pain in patients with fecal elastase-1 concentrations $<100 \mu \mathrm{g} / \mathrm{g}$ stool. ${ }^{74}$ However, the study was conducted in an open-label manner without a placebo control group. Therefore, further studies are needed to confirm whether PERT improves clinical symptoms such as diarrhea in patients with irritable bowel syndrome.

\section{Chronic inflammatory bowel disease}

Crohn's disease and ulcerative colitis, two of the most common types of inflammatory bowel disease, are characterized by a number of extraintestinal manifestations. ${ }^{75}$ The association between inflammatory bowel disease and the pancreas is demonstrated in many reports showing altered pancreatic exocrine function and PEI in patients with inflammatory bowel disease. In fact, Angelini et al ${ }^{76}$ reported that pancreatic dysfunction is more common than is generally recognized in patients with Crohn's disease. In their study, 
$11 / 27$ patients had bicarbonate plus enzyme insufficiency or enzyme insufficiency alone, while $18 / 27$ patients had isolated decreased lipase levels. Pancreatic insufficiency is a frequent complication in patients with inflammatory bowel disease, particularly in patients with loose stools, a large number of daily bowel movements, and a history of surgery. ${ }^{77}$ These findings point towards a high risk of pancreatitis in patients with inflammatory bowel disease. Awareness of this risk could significantly improve the management of inflammatory bowel disease. ${ }^{78}$

\section{Zollinger-Ellison syndrome and gastrectomy}

Zollinger-Ellison syndrome is a rare disease characterized by hypersecretion of gastrin from non-beta cell islet tumors in the pancreas, leading to refractory peptic ulcers and diarrhea caused by inactivation of pancreatic enzymes. Proton pump inhibitor therapy is effective in controlling gastric acid hypersecretion, ${ }^{79}$ and reduces the morbidity and potential mortality associated with this syndrome. ${ }^{80}$ Interestingly, Zollinger-Ellison syndrome mimics PEI in terms of clinical symptom, probably via gastrointestinal dysfunction. Therefore, in patients who experience no improvement in diarrhea or PEI following PERT, Zollinger-Ellison syndrome or multiple endocrine neoplasia type 1 should be considered as potential causes.

PEI is commonly observed after pancreatic resection and after partial or total gastrectomy. ${ }^{81}$ PERT is indicated for patients with clinically evident steatorrhea, weight loss, or maldigestion-related symptoms after gastric or duodenal surgery. ${ }^{82}$ However, relatively few studies have focused on these issues, so treatment with pancrelipase gastrectomy should be considered on an individual patient basis.

\section{Type I and type 2 diabetes}

As described above, pancreatic diabetes is a type of pancreatic disease. Numerous clinical studies have actually shown that as many as $50 \%$ of patients with type 1 diabetes and $20 \%$ of patients with type 2 diabetes had clinical features of PEI. ${ }^{13}$ Furthermore, intriguingly, Nues et $\mathrm{al}^{13}$ showed that, compared with lean patients with diabetes, obese patients (body mass index $>25.0 \mathrm{~kg} / \mathrm{m}^{2}$ ) with diabetes were at increased risk for PEI, and that steatorrhea was detected in approximately one-third of obese patients with diabetes and low fecal elastase-1 levels. The etiology of the "traditional" forms of diabetes, particularly type 2 diabetes, differs from that of pancreatic diabetes. Nevertheless, up to $9 \%$ of all cases of diabetes were found to be caused by pancreatic diabetes, much higher than is commonly believed, suggesting that some cases of pancreatic diabetes are misdiagnosed type 1 or type 2 diabetes. ${ }^{59,60}$

Although the mechanism by which people with diabetes develop PEI is largely unclear, one plausible reason is that insulin has a trophic effect on pancreatic acinar cells. ${ }^{83}$ Thus, the lack of or reduced secretion of insulin in the pancreas may lead to inactivity of acinar cells, inducing atrophic changes that subsequently reduce exocrine function, resulting in PEI. In addition, in type 2 diabetes, insulin resistance and resultant hyperinsulinemia might downregulate insulin receptor expression in acinar cells. ${ }^{84}$ Diabetic neuropathy may also induce functional and morphological alterations that could result in PEI, as proposed by Hardit et al. Alternatively, an antibody against islet cells can cross-react with acinar cells and disrupt its functions.

Taken together, PEI appears to be a complication of type 1 and type 2 diabetes. Given that PEI may be a complication of diabetes and that hyperglycemia and/or insulin inactivity (caused by hypoinsulinemia or insulin resistance) induce pancreatic exocrine dysfunction and the development of PEI, appropriate antidiabetic therapies are important, irrespective of the type of diabetes (Figure 1).

In the context of PERT, a 16-week randomized study in 80 patients with type 1 diabetes and low fecal elastase- 1 concentrations found no significant differences in $\mathrm{HbA}_{1 \mathrm{c}}$, fasting glucose levels, clinical parameters, or safety parameters between patients treated with Creon $(4 \times 10,000$ Fédération Internationale Pharmaceutique units) or placebo. ${ }^{85}$ However, the frequency of hypoglycemia was lower in patients treated with Creon. Unfortunately, no other clinical study has examined the potential utility of PERT for the management of PEI in patients with diabetes. Consequently, until further evidence is reported, PERT with pancrelipase should be considered on an individual patient basis, with appropriate assessment of PEI and abnormal glucose metabolism.

Another factor that should be considered is that PERT is likely to increase the effects of incretins, irrespective of glycemic status. ${ }^{86}$ Indeed, in that study, the response of total glucagon-like peptide-1 was increased after pancreatic enzyme substitution (Creon, pancreatin) and was associated with increased plasma insulin levels and total insulin secretion without changes in the area under the plasma glucose concentration-time curve. These results suggest that PERT may improve glucose metabolism by restoring the activity of incretins, such as glucagon-like peptide-1, in patients with chronic pancreatitis. Unfortunately, it is still unknown whether diabetes secondary to conditions associated with hypersecretion of glucocorticoid or thyroid hormones could result in the development of PEI, or whether PERT could be beneficial in these settings. 


\section{PEI in elderly individuals}

Aging is associated with changes in pancreatic enzyme secretion. For example, Laugier et a ${ }^{87}$ reported that concentrations of pancreatic enzymes decreased linearly with age from 30 years of age in apparently healthy individuals. Vellas et $a^{18}$ reported that bicarbonate, lipase, and chymotrypsin concentrations in elderly subjects with a mean age of 72 years were significantly reduced by $17 \%, 15 \%$, and $23 \%$, respectively $(P<0.05)$, as compared with those in younger subjects (mean age 36 years). Rothenbacher et $\mathrm{al}^{16}$ showed that prevalence of PEI, defined as low elastase- 1 concentrations, increases with age. PEI was detected in $6.0 \%$ of patients aged $50-54$ years, but in $13.4 \%$ for those aged $70-75$ years $(P=0.005)$. Additionally, the prevalence of PEI seemed to be higher in men than in women. They also found that smoking was an independent risk factor for PEI, whereas the use of an angiotensin-converting enzyme inhibitor was protective against PEI. In another study, approximately $20 \%$ of apparently healthy individuals $\geq 60$ years of age without history of gastrointestinal disorder, surgery, or diabetes had PEI defined, as fecal elastase- 1 concentrations of $<100 \mu \mathrm{g} / \mathrm{g} .{ }^{17}$

\section{PEI in other clinically relevant conditions}

In addition to the conditions described above, PEI occurs in patients with human immunodeficiency virus infection, alcohol-related liver cirrhosis, ${ }^{89,90}$ and end-stage renal disease $^{91,92}$ (Figure 2), all of which are associated with high mortality rates. However, the underlying mechanisms are still unknown. Furthermore, the clinical characteristics and pathophysiology of PEI in these diseases are likely to differ based on the nature of the disease and potential relationship with the gastrointestinal and pancreatic systems. Thus, the pathophysiology of PEIs and the possible efficacy of PERT should be considered for each disease and condition separately.

\section{Conclusion}

In patients with pancreatic diseases, particularly chronic pancreatitis and cystic fibrosis, PERT with approved pancrelipase products should be considered the first-line therapy for PEI. To achieve adequate clinical effects with these agents, a gradual increase in dosage and coadministration of a gastric acid suppressor may be necessary. However, large long-term studies are needed to explore the optimal treatment of patients with PEI, and to examine the effects of PERT with pancrelipase products on mortality and morbidity. PERT may also be useful in other diseases associated with PEI, including extrapancreatic diseases, such as gastrointestinal diseases and diabetes (except pancreatic diabetes), and in elderly subjects. Although we are still awaiting robust clinical evidence, the use of PERT should be considered on an individual patient basis. In terms of the pancreatic exocrine-endocrine relationship, clinicians need to become more aware of the risk of pancreatic diabetes, another crucial complication of pancreas disease associated with poor morbidity and mortality. Further studies are needed to explore the clinical relevance and appropriate treatment of this disorder.

\section{Disclosure}

The authors report no conflicts of interest in this work.

\section{References}

1. Keller J, Aghdassi AA, Lerch MM, Mayerle JV, Layer P. Tests of pancreatic exocrine function-clinical significance in pancreatic and nonpancreatic disorders. Best Pract Res Clin Gastroenterol. 2009;23(3): 425-439.

2. Rhodes B, Nash EF, Tullis E, et al. Prevalence of dyslipidemia in adults with cystic fibrosis. J Cyst Fibros. 2010;9(1):24-28.

3. Domínguez Muñoz JE. Diagnosis of chronic pancreatitis: functional testing. Best Pract Res Clin Gastroenterol. 2010;24(3):233-241.

4. Hammer HF. Pancreatic exocrine insufficiency: diagnostic evaluation and replacement therapy with pancreatic enzymes. Dig Dis. 2010; 28(2):339-343.

5. Leeds JS, Oppong K, Sanders DS. The role of fecal elastase-1 in detecting exocrine pancreatic disease. Nat Rev Gastroenterol Hepatol. 2011;8(7):405-415.

6. Taylor JR, Gardner TB, Waljee AK, Dimagno MJ, Schoenfeld PS Systematic review: efficacy and safety of pancreatic enzyme supplements for exocrine pancreatic insufficiency. Aliment Pharmacol Ther. 2010;31(1):57-72.

7. Dhanasekaran R, Toskes PP. Pancrelipase for pancreatic disorders: an update. Drugs Today (Barc). 2010;46(11):855-866.

8. Krishnamurty DM, Rabiee A, Jagannath SB, Andersen DK. Delayed release pancrelipase for treatment of pancreatic exocrine insufficiency associated with chronic pancreatitis. Ther Clin Risk Manag. 2009; 5(3):507-520.

9. Application for the inclusion of pancreatic enzymes in the World Health Organisation Model List of Essential Medicines. Presented at the Second Meeting of the Subcommittee of the Expert Committee on the Selection and Use of Essential Medicines, 29 September-3 October, Geneva, Switzerland, 2008.

10. Layer P, Keller J. Lipase supplementation therapy: standards, alternatives, and perspectives. Pancreas. 2003;26(1):1-7.

11. Domínguez-Muñoz JE. Pancreatic enzyme therapy for pancreatic exocrine insufficiency. Gastroenterol Hepatol (N Y). 2011;7(6): 401-403.

12. Domínguez-Muñoz JE. Pancreatic exocrine insufficiency: diagnosis and treatment. J Gastroenterol Hepatol. 2011;26 Suppl 2:12-16.

13. Nunes AC, Pontes JM, Rosa A, Gomes L, Carvalheiro M, Freitas D. Screening for pancreatic exocrine insufficiency in patients with diabetes mellitus. Am J Gastroenterol. 2003;98(12):2672-2675.

14. Hardt PD, Hauenschild A, Jaeger C, et al. High prevalence of steatorrhea in 101 diabetic patients likely to suffer from exocrine pancreatic insufficiency according to low fecal elastase 1 concentrations: a prospective multicenter study. Dig Dis Sci. 2003;48(9):1688-1692.

15. Hardt PD, Ewald N. Exocrine pancreatic insufficiency in diabetes mellitus: a complication of diabetic neuropathy or a different type of diabetes? Exp Diabetes Res. 2011;2011:761950. 
16. Rothenbacher D, Löw M, Hardt PD, Klör HU, Ziegler H, Brenner H. Prevalence and determinants of exocrine pancreatic insufficiency among older adults: results of a population-based study. Scand J Gastroenterol. 2005;40(6):697-704.

17. Herzig KH, Purhonen AK, Räsänen KM, et al. Fecal pancreatic elastase-1 levels in older individuals without known gastrointestinal diseases or diabetes mellitus. BMC Geriatr. 2011;11:4.

18. Andersen BN, Pedersen NT, Scheel J, Worning H. Incidence of alcoholic chronic pancreatitis in Copenhagen. Scand J Gastroenterol. 1982;17(2):247-252.

19. Kopelman P. Health risks associated with overweight and obesity. Obes Rev. 2007;8 Suppl 1:13-17.

20. Dixon JB. The effect of obesity on health outcomes. Mol Cell Endocrinol. 2010;316(2):104-108.

21. Chowdhury RS, Forsmark CE. Review article: pancreatic function testing. Aliment Pharmacol Ther. 2003;17(6):733-750.

22. Sikkens EC, Cahen DL, Kuipers EJ, Bruno MJ. Pancreatic enzyme replacement therapy in chronic pancreatitis. Best Pract Res Clin Gastroenterol. 2010;24(3):337-347.

23. Lüth S, Teyssen S, Forssmann K, Kölbel C, Krummenauer F, Singer MV. Fecal elastase-1 determination: 'gold standard' of indirect pancreatic function tests? Scand J Gastroenterol. 2001;36(10):1092-1099.

24. DiMagno EP, Go VL, Summerskill WH. Relations between pancreatic enzyme ouputs and malabsorption in severe pancreatic insufficiency. N Engl J Med. 1973;288(16):813-815.

25. Lankisch PG, Lembcke B, Wemken G, Creutzfeldt W. Functional reserve capacity of the exocrine pancreas. Digestion. 1986;35(3): $175-181$.

26. Ammann RW, Muellhaupt B. The natural history of pain in alcoholic chronic pancreatitis. Gastroenterology. 1999;116(5):1132-1140.

27. Imoto M, DiMagno EP. Cigarette smoking increases the risk of pancreatic calcification in late-onset but not early-onset idiopathic chronic pancreatitis. Pancreas. 2000;21(2):115-119.

28. Law R, Parsi M, Lopez R, Zuccaro G, Stevens T. Cigarette smoking is independently associated with chronic pancreatitis. Pancreatology. 2010;10(1):54-59.

29. Nakajima K, Nemoto T, Muneyuki T, Kakei M, Fuchigami H, Munakata H. Low serum amylase in association with metabolic syndrome and diabetes: a community-based study. Cardiovasc Diabetol. 2011;10:34

30. Mössner J, Keim V. Pancreatic enzyme therapy. Dtsch Arztebl Int. 2010;108(34-35):578-582.

31. Nair RJ, Lawler L, Miller MR. Chronic pancreatitis. Am Fam Physician. 2007;76(11):1679-1688.

32. Safdi M, Bekal PK, Martin S, Saeed ZA, Burton F, Toskes PP. The effects of oral pancreatic enzymes (Creon 10 capsule) on steatorrhea: a multicenter, placebo-controlled, parallel group trial in subjects with chronic pancreatitis. Pancreas. 2006;33(2):156-162.

33. Whitcomb DC, Lehman GA, Vasileva G, et al. Pancrelipase delayedrelease capsules (CREON) for exocrine pancreatic insufficiency due to chronic pancreatitis or pancreatic surgery: a double-blind randomized trial. Am J Gastroenterol. 2010;105(10):2276-2286.

34. Gubergrits N, Malecka-Panas E, Lehman GA, et al. A 6-month, open-label clinical trial of pancrelipase delayed-release capsules (Creon) in patients with exocrine pancreatic insufficiency due to chronic pancreatitis or pancreatic surgery. Aliment Pharmacol Ther. 2011;33(10):1152-1161.

35. Toskes PP, Secci A, Thieroff-Ekerdt R; ZENPEP Study Group. Efficacy of a novel pancreatic enzyme product, EUR-1008 (Zenpep), in patients with exocrine pancreatic insufficiency due to chronic pancreatitis. Pancreas. 2011;40(3):376-382.

36. Giuliano CA, Dehoorne-Smith ML, Kale-Pradhan PB. Pancreatic enzyme products: digesting the changes. Ann Pharmacother. 2011; 45(5):658-666.

37. Nøjgaard C, Bendtsen F, Becker U, Andersen JR, Holst C, Matzen P. Danish patients with chronic pancreatitis have a four-fold higher mortality rate than the Danish population. Clin Gastroenterol Hepatol. 2010;8(4):384-390.
38. Baker SS. Delayed release pancrelipase for the treatment of pancreatic exocrine insufficiency associated with cystic fibrosis. Ther Clin Risk Manag. 2008;4(5):1079-1084.

39. Sinaasappel M, Stern M, Littlewood J, et al. Nutrition in patients with cystic fibrosis: a European consensus. J Cyst Fibros. 2002;1(2):51-75.

40. Hayek KM. Medical nutrition therapy for cystic fibrosis: beyond pancreatic enzyme replacement therapy. JAm Diet Assoc. 2006;106(8): $1186-1188$.

41. Stern RC, Eisenberg JD, Wagener JS, et al. A comparison of the efficacy and tolerance of pancrelipase and placebo in the treatment of steatorrhea in cystic fibrosis patients with clinical exocrine pancreatic insufficiency. Am J Gastroenterol. 2000;95(8):1932-1938.

42. Trapnell BC, Maguiness K, Graff GR, Boyd D, Beckmann K, Caras S. Efficacy and safety of Creon 24,000 in subjects with exocrine pancreatic insufficiency due to cystic fibrosis. J Cyst Fibros. 2009;8(6): 370-377.

43. Colombo C, Fredella C, Russo MC, et al. Efficacy and tolerability of Creon for children in infants and toddlers with pancreatic exocrine insufficiency caused by cystic fibrosis: an open-label, single-arm, multicenter study. Pancreas. 2009;38(6):693-699.

44. Wooldridge JL, Heubi JE, Amaro-Galvez R, et al. EUR-1008 pancreatic enzyme replacement is safe and effective in patients with cystic fibrosis and pancreatic insufficiency. J Cyst Fibros. 2009;8(6): 405-417.

45. Graff GR, Maguiness K, McNamara J, et al. Efficacy and tolerability of a new formulation of pancrelipase delayed-release capsules in children aged 7 to 11 years with exocrine pancreatic insufficiency and cystic fibrosis: a multicenter, randomized, double-blind, placebo-controlled, two-period crossover, superiority study. Clin Ther. 2010;32(1): 89-103.

46. Trapnell BC, Strausbaugh SD, Woo MS, et al. Efficacy and safety of Pancreaze ${ }^{\circledR}$ for treatment of exocrine pancreatic insufficiency due to cystic fibrosis. J Cyst Fibros. 2011;10(5):350-356.

47. Olveira G, Olveira C. Nutrition, cystic fibrosis and the digestive tract. Nutr Hosp. 2008;23 Suppl 2:71-86.

48. Van Hoozen CM, Peeke PG, Taubeneck M, Frey CF, Halsted CH. Efficacy of enzyme supplementation after surgery for chronic pancreatitis. Pancreas. 1997;14(2):174-180.

49. Ferrie S, Graham C, Hoyle M. Pancreatic enzyme supplementation for patients receiving enteral feeds. Nutr Clin Pract. 2011;26(3): 349-351.

50. Shlieout G, Koerner A, Maffert M, Forssmann K, Caras S. Administration of Creon ${ }^{\mathbb{B}}$ pancrelipase pellets via gastrostomy tube is feasible with no loss of gastric resistance or lipase activity: an in vitro study. Clin Drug Investig. 2011;31(7): $1-\mathrm{e} 7$.

51. Davidson GP, Hassel FM, Crozier D, Corey M, Forstner GG. Iatrogenic hyperuricemia in children with cystic fibrosis. J Pediatr. 1978;93(6): 976-978.

52. Lloyd-Still JD, Beno DW, Kimura RM. Cystic fibrosis colonopathy. Curr Gastroenterol Rep. 1999;1(3):231-237.

53. Ferrone M, Raimondo M, Scolapio JS. Pancreatic enzyme pharmacotherapy. Pharmacotherapy. 2007;27(6):910-920.

54. Stallings VA, Stark LJ, Robinson KA, et al. Evidence-based practice recommendations for nutrition-related management of children and adults with cystic fibrosis and pancreatic insufficiency: results of a systematic review. $J$ Am Diet Assoc. 2008;108(5): 832-839.

55. Prescott P, Bakowski MT. Pathogenesis of fibrosing colonopathy: the role of methacrylic acid copolymer. Pharmacoepidemiol Drug Saf. 1999;8(6):377-384

56. Lee J, Ip W, Durie P. Is fibrosing colonopathy an immune-mediated disease? Arch Dis Child. 1997;77(1):66-70.

57. Kahl S, Malfertheiner P. Exocrine and endocrine pancreatic insufficiency after pancreatic surgery. Best Pract Res Clin Gastroenterol. 2004;18(5):947-955.

58. Slezak LA, Andersen DK. Pancreatic resection: effects on glucose metabolism. World J Surg. 2001;25(4):452-460. 
59. Hardt PD, Brendel MD, Kloer HU, Bretzel RG. Is pancreatic diabetes (type 3c diabetes) underdiagnosed and misdiagnosed? Diabetes Care. 2008;31 Suppl 2:S165-S169.

60. Ewald N, Kaufmann C, Raspe A, Kloer HU, Bretzel RG, Hardt PD. Prevalence of diabetes mellitus secondary to pancreatic diseases (type 3c). Diabetes Metab Res Rev. 2012;28(4):338-342.

61. Ito T, Otsuki M, Igarashi H, et al. Epidemiological study of pancreatic diabetes in Japan in 2005: a nationwide study. Pancreas. 2010;39(6): 829-835.

62. Cui Y, Andersen DK. Pancreatogenic diabetes: special considerations for management. Pancreatology. 2011;11(3):279-294.

63. Eliasson B, Attvall S, Taskinen MR, Smith U. The insulin resistance syndrome in smokers is related to smoking habits. Arterioscler Thromb. 1994;14(12):1946-1950.

64. Chiolero A, Faeh D, Paccaud F, Cornuz J. Consequences of smoking for body weight, body fat distribution, and insulin resistance. Am J Clin Nutr. 2008;87(4):801-809.

65. Rashtak S, Murray JA. Review article: coeliac disease, new approaches to therapy. Aliment Pharmacol Ther. February 13, 2012. [Epub ahead of print.]

66. Fine KD, Meyer RL, Lee EL. The prevalence and causes of chronic diarrhea in patients with celiac sprue treated with a gluten-free diet. Gastroenterology. 1997;112(6):1830-1838.

67. Kurppa K, Collin P, Mäki M, Kaukinen K. Celiac disease and healthrelated quality of life. Expert Rev Gastroenterol Hepatol. 2011;5(1): 83-90.

68. Fasano A, Berti I, Geraduzzi T, et al. Prevalence of celiac disease in at-risk and not-at-risk groups in the United States. Arch Intern Med. 2003;163(3):286-292.

69. Green PH, Jabri B. Coeliac disease. Lancet. 2003;362(9381): 383-391.

70. Evans KE, Leeds JS, Morley S, Sanders DS. Pancreatic insufficiency in adult celiac disease: do patients require long-term enzyme supplementation? Dig Dis Sci. 2010;55(10):2999-3004.

71. Carroccio A, Iacono G, Montalto G, et al. Pancreatic insufficiency in celiac disease is not dependent on nutritional status. Dig Dis Sci. 1994; 39(10):2235-2242.

72. Leeds JS, Hopper AD, Hurlstone DP, et al. Is exocrine pancreatic insufficiency in adult coeliac disease a cause of persisting symptoms? Aliment Pharmacol Ther. 2007;25(3):265-271.

73. Kellow JE. IBS: do we need to exclude exocrine pancreatic insufficiency in IBS? Nat Rev Gastroenterol Hepatol. 2010;7(9):479-480.

74. Leeds JS, Hopper AD, Sidhu R, et al. Some patients with irritable bowel syndrome may have exocrine pancreatic insufficiency. Clin Gastroenterol Hepatol. 2010;8(5):433-438.

75. Pitchumoni CS, Rubin A, Das K. Pancreatitis in inflammatory bowel diseases. J Clin Gastroenterol. 2010;44(4):246-253.
76. Angelini G, Cavallini G, Bovo P, et al. Pancreatic function in chronic inflammatory bowel disease. Int J Pancreatol. 1988;3(2-3):185-193.

77. Maconi G, Dominici R, Molteni M, et al. Prevalence of pancreatic insufficiency in inflammatory bowel diseases. Assessment by fecal elastase-1. Dig Dis Sci. 2008;53(1):262-270.

78. Seyrig JA, Jian R, Modigliani R, et al. Idiopathic pancreatitis associated with inflammatory bowel disease. Dig Dis Sci. 1985;30(12): 1121-1126.

79. Nieto JM, Pisegna JR. The role of proton pump inhibitors in the treatment of Zollinger-Ellison syndrome. Expert Opin Pharmacother. 2006;7(2):169-175.

80. Tomassetti P, Campana D, Piscitelli L, et al. Treatment of ZollingerEllison syndrome. World J Gastroenterol. 2005;11(35):5423-5432.

81. Friess H, Böhm J, Ebert M, Büchler M. Enzyme treatment after gastrointestinal surgery. Digestion. 1993;54 Suppl 2:48-53.

82. Domínguez-Muñoz JE. Pancreatic enzyme replacement therapy: exocrine pancreatic insufficiency after gastrointestinal surgery. $H P B$ (Oxford). 2009;11 Suppl 3:3-6.

83. Williams JA, Goldfine ID. The insulin-pancreatic acinar axis. Diabetes. 1985;34(10):980-986.

84. Mössner J, Logsdon CD, Goldfine ID, Williams JA. Regulation of pancreatic acinar cell insulin receptors by insulin. Am J Physiol. 1984;247(2 Pt 1):G155-G160.

85. Ewald N, Bretzel RG, Fantus IG, et al. Pancreatin therapy in patients with insulin-treated diabetes mellitus and exocrine pancreatic insufficiency according to low fecal elastase 1 concentrations. Results of a prospective multi-centre trial. Diabetes Metab Res Rev. 2007;23(5):386-391.

86. Knop FK, Vilsbøll T, Larsen S, et al. Increased postprandial responses of GLP-1 and GIP in patients with chronic pancreatitis and steatorrhea following pancreatic enzyme substitution. Am J Physiol Endocrinol Metab. 2007;292(1):E324-E330.

87. Laugier R, Bernard J, Berthezene P, Dupuy P. Changes in pancreatic exocrine secretion with age: pancreatic exocrine secretion does decrease in the elderly. Digestion. 1991;50:202-211.

88. Vellas B, Balas D, Moreau J, et al. Exocrine pancreatic secretion in the elderly. Int J Pancreatol. 1988;3(6):497-502.

89. Angelirni G, Merigo F, Degani G, et al. Association of chronic alcoholic liver and pancreatic disease: a prospective study. Am J Gastroenterol. 1985;80(12):998-1003.

90. Hayakawa T, Kondo T, Shibata T, et al. Exocrine pancreatic function in chronic liver diseases. Am J Gastroenterol. 1991;86(2):201-204.

91. Ventrucci M, Campieri C, Di Stefano M, et al. Alterations of exocrine pancreas in end-stage renal disease. Do they reflect a clinically relevant uremic pancreopathy? Dig Dis Sci. 1995;40(12):2576-2581.

92. Griesche-Philippi J, Otto J, Schwörer H, Maisonneuve P, Lankisch PG Exocrine pancreatic function in patients with end-stage renal disease. Clin Nephrol. 2010;74(6):457-464.
Core Evidence

\section{Publish your work in this journal}

Core Evidence is an international, peer-reviewed open-access journal evaluating the evidence underlying the potential place in therapy of drugs throughout their development lifecycle from preclinical to postlaunch. The focus of each review is to evaluate the case for a new drug or class in outcome terms in specific indications and patient groups.

\section{Dovepress}

The manuscript management system is completely online and includes a very quick and fair peer-review system, which is all easy to use. Visit http://www.dovepress.com/testimonials.php to read real quotes from published authors. 